ADLFI. Archéologie de la France -

une revue Gallia

Auvergne | 2007

\title{
Canton de Billom
}

Frédéric Trément

\section{OpenEdition}

Journals

Édition électronique

URL : http://journals.openedition.org/adlfi/5941

ISSN : 2114-0502

Éditeur

Ministère de la culture

Référence électronique

Frédéric Trément, «Canton de Billom », ADLFI. Archéologie de la France - Informations [En ligne], Auvergne, mis en ligne le 01 mars 2007, consulté le 19 avril 2019. URL : http://

journals.openedition.org/adlfi/5941

Ce document a été généré automatiquement le 19 avril 2019

(c) Ministère de la Culture et de la Communication, CNRS 


\title{
Canton de Billom
}

\author{
Frédéric Trément
}

Identifiant de l'opération archéologique : 140

Date de l'opération : 2005 - 2007 (PI)

1 La prospection systématique du canton de Billom s'est poursuivie pour la troisième année consécutive durant l'hiver 2007 (BSR 2005, p. 114-115; BSR 2006, p. 123-125, Frédéric Trément). Deux stages universitaires, d'une durée de neuf jours chacun, ont été organisés du 26 février au 6 mars et du 10 au 18 mars. Ils ont regroupé une vingtaine d'étudiants d'archéologie.

Quatre grandes zones de prospection ont été privilégiées cette année. La première zone est localisée au nord de Billom (communes de Vassel, Espirat, Moissat) et concerne exclusivement des parcelles situées en zone basse (altitude moyenne: $330 \mathrm{~m}$ ). La deuxième zone correspond au versant septentrional du «Petit Turluron » (commune de Chas). La troisième zone a permis de poursuivre l'exploration du secteur de Marcillat, au sud $\mathrm{du}$ «Gros Turluron ». La dernière zone prospectée a initié l'étude du «bassin des Neuf-Fontaines » à Saint-Georges-sur-Allier.

3 Au total, ce sont 305 ha qui ont été prospectés systématiquement, avec un espacement de $10 \mathrm{~m}$ maximum entre les prospecteurs. Plusieurs dizaines de sites et indices de sites inédits ont été identifiés, notamment de l'âge du Bronze, de l'âge du Fer et de l'époque romaine, ainsi que plusieurs sites du haut et du bas Moyen Âge.

Trément Frédéric 
INDEX

Index géographique : Auvergne, Puy-de-Dôme (63), Billom

Index chronologique : âge du Bronze, âge du Fer, Empire romain, Moyen Âge operation Prospection inventaire (PI)

\section{AUTEURS}

\section{FRÉDÉRIC TRÉMENT}

ENS 